\title{
GEOTECNOLOGIAS NO DIAGNÓSTICO DE CONFLITOS DE USO DO SOLO DE UMA MICROBACIA DO MUNICÍPIO DE ALTA FLORESTA - MT
}

\author{
GEOTECNOLOGY IN ASSESSING CONFLICTS OF USE OF THE SOIL FROM A MICROBASIN OF \\ THE CITY OF ALTA FLORESTA - MT
}

\author{
Emanoel Junior da Silva Nunes ${ }^{1}$ Edgley Pereira da Silva ${ }^{2}$ Eliana de Souza ${ }^{3}$ \\ Jesulino Alves da Rocha Filho ${ }^{4}$ Diana Suzete Nunes da Silva ${ }^{5}$
}

\begin{abstract}
RESUMO
Objetivou-se com este estudo usar geotecnologias para mapear a cobertura do solo e diagnosticar conflitos de uso da terra em áreas de preservação permanente (APPs) de uma microbacia de 17.759 ha, localizada no município de Alta Floresta - MT. A delimitação das APPs teve como base a Lei Complementar no 412 do estado de Mato Grosso, de 13 de Dezembro de 2010. Para tanto, utilizou-se mapa de hidrografia e modelo digital de elevação, para a delimitação da bacia e nessa as áreas de preservação. O mapeamento da cobertura do solo foi realizado por classificação supervisionada pelo algoritmo MaxVer no software ENVI 4.2, em uma imagem orbital de alta resolução espacial, do sensor SPOT 5, adquirida no ano de 2008. O processamento dos dados, ajuste das projeções, criação dos arquivos vetoriais e cruzamento entre os mapas de cobertura do solo e áreas de preservação foram realizados no software ArcGIS 9.2. As classes de cobertura do solo mapeadas foram: floresta, pastagem, água, solo exposto e ocupação urbana. A área total de APPs (1.966,51 ha) representa $11,1 \%$ da área da microbacia, dos quais a maior parte de uso indevido ocorre com pastagem (47,7\%); áreas de floresta representam 39,5\% do total das APPs. As classes solo exposto e ocupação urbana representam respectivamente, 26,5 e 110,1 ha, equivalendo $6,9 \%$ da área. Concluiu-se que a imagem utilizada mostrou-se satisfatória para o mapeamento das classes de cobertura do solo na área estudada. O mapeamento e cruzamento das informações obtidas mostraram que um total 1.074,92 ha está com uso conflitante com a legislação ambiental vigente, pois apresenta alguma forma de ação antrópica. As áreas com uso indevido cobre 54,6 \% das APPs e são representadas pelas fisionomias de pastagem, solo exposto e ocupação urbana.
\end{abstract}

Palavras-chave: áreas de preservação permanente; classificação supervisionada; legislação ambiental; cobertura do solo.

\section{ABSTRACT}

The aim of this study is the use of geotechnology in mapping the soil cover and to assess conflicts of land use in permanent preservation areas (PPA) of a microbasin with an area of 17,759 ha located in the municipality of Alta Floresta, in Mato Grosso State. The demarcation of PPA was based on the Complementary Law No. 412 of the state of Mato Grosso, December 13, 2010. To carry out the work, it were used hydrographic map and digital elevation model to delimit the microbasin and the preservation areas.

1 Engenheiro Florestal, Mestrando em Solos e Nutrição de Plantas, Escola Superior de Agricultura "Luiz de Queiroz" USP, Av. Pádua Dias, 11, CEP 13418-900, Piracicaba (SP), Brasil. jr.emanoel@usp.br

2 Engenheiro Agrônomo, Dr., Professor do Departamento Agronomia, Universidade do Estado de Mato Grosso, Campus Alta Floresta, Av. Rogério Silva, s/n, Jd. Flamboyant, CEP 78580-000, Alta Floresta (MT), Brasil. edyps2004@hotmail.com

3 Geógrafa, Dr ${ }^{\mathrm{a}}$., Departamento de Solos na Universidade Federal de Viçosa, Av. P.H. Rolfs, s/n, CEP 36570-000, Viçosa (MG), Brasil. elianadsouza@yahoo.com.br

4 Engenheiro Florestal, Analista Ambiental e SIG, Companhia Hidrelétrica Telles Pires, Av. Ayrton Senna, 377, CEP 78590-000, Paranaíta (MT), Brasil. jesulinoarf@hotmail.com

5 Engenheira Florestal, Mestranda em Engenharia Florestal, Universidade Federal de Lavras, Caixa Postal 3037, CEP 37200-000, Lavras (MG), Brasil. disuzete.florestal@posgrad.ufla.br 
The mapping of land cover was carried out by means of supervised classification with the algorithm MaxVer using Envi 4.2 software, in a satellite image of high spatial resolution from SPOT 5 sensor, acquired in 2008. The data processing, adjustment of the projections, file creation and crossing of vector-maps of land cover and preservations areas were done in ArcGIS 9.2. The land cover classes mapped are the following: forest, pasture, water, bare soil and urban settlement. The total area of PPA $(1,966.51$ ha) represents $11.1 \%$ of the microbasin area, of which most of misuse occurs with pasture $(47.7 \%)$, forest areas represent 39.5 $\%$ of total PPA. The class of exposed soil and urban occupation represent respectively 26.5 and 110.1 ha, equivalent $6.9 \%$ of the preservation area. It could be concluded that, the image used, was found satisfactory for mapping the land cover classes on the study area. The mapping and crossing of information showed that an area of 1,074.92 ha has conflict of use according to the current environmental legislation, as there are any forms of human activity. The areas with improper use account for $54.6 \%$ of the total PPA and are represented by pasture, bare soil and $54.6 \%$ of the total PPA and are represented by pasture, bare soil and urban settlement.

Keywords: permanent preservation areas; supervised classification; environmental law; soil coverage.

\section{INTRODUÇÃO}

Os efeitos da degradação do solo, da poluição das águas, e de muitos outros tipos de danos ambientais, assim como, o aumento da consciência na população da sua dependência do meio ambiente, em relação aos recursos naturais e à qualidade de vida, levaram, nas últimas décadas, à revisão, criação e ampliação de uma legislação disciplinadora do uso do ambiente (ATTANASIO et al., 2006). O Brasil, embora tenha participado das grandes conferências, somente em 1981 promulgou a Lei 6.938, que estabelece a Política Nacional de Meio Ambiente (PNMA). Entre os vários mecanismos legais destinados a reduzir os efeitos causados por diversas atividades impactantes, destacam-se a Lei 4.771 de 1965 e a Resolução ${ }^{\circ}$ 303 do CONAMA, que institui o Código florestal brasileiro. A aplicação dessa lei, no estado de Mato Grosso, é feita segundo a Lei Complementar $n^{\circ}$ 412, de 13 de Dezembro de 2010 que regulamenta a delimitação de Áreas de Preservação Permanente (APP) no estado.

O desmatamento para fins agropecuários tem resultado na sua fragmentação, condicionando a essas áreas novas características, constituindose em mosaicos de tamanhos e formas diferentes. Consequentemente, a esse fenômeno caracterizado pela remoção das áreas de florestas nativas para fins agropecuários, por se tratar de ambientes com alta diversidade biológica de espécies e pela sua função natural como protetora dos recursos hídricos, dentre os impactos ambientais ocasionados, evidenciam-se a redução da biodiversidade, o distúrbio do regime hidrológico das bacias hidrográficas, as alterações climáticas, a degradação dos recursos naturais e, sob a ótica do desenvolvimento sustentável, a depreciação da qualidade de vida da população (VIANA et al., 1992).

Assim, estudos relacionados com os aspectos físico-ambientais, em particular dos diferentes níveis de fragmentação da cobertura florestal, tornam-se essenciais para que medidas mitigadoras e compensatórias possam ser adotadas, objetivando reduzir ou evitar prejuízos sobre os diferentes compartimentos da natureza.

Segundo Schneider e Tartaruga (2004), técnicas informatizadas de análise espacial passaram a obter elevado destaque e serem apontadas por muitos estudiosos como de fundamental relevância para se compreender o dinamismo do uso e da ocupação das terras.

Os sensores remotos são equipamentos que captam e registram a energia refletida ou emitida pelos elementos da superfície terrestre. Dependendo das suas características, eles podem ser instalados em plataformas terrestres, aéreas (balões, helicópteros e aviões) e orbitais (satélites artificiais) (FLORENZANO, 2002).

De acordo com Carvalho et al. (2003), as ferramentas computacionais para geoprocessamento, chamadas de Sistemas de Informação Geográfica GIS - sigla em inglês para SIG -, permitem, realizar análises complexas, ao integrar dados de diversas fontes e ao criar bancos de dados georreferenciados tornam ainda possível automatizar a produção de documentos cartográficos.

O monitoramento das áreas de preservação permanente tem sido um grande desafio sob o aspecto técnico e econômico, pois os critérios 
de delimitação com base na topografia exigem o envolvimento de pessoal especializado e de informações detalhadas da unidade espacial em análise. Entretanto, com o desenvolvimento de sofisticados algoritmos e a sua incorporação ao conjunto de funções dos Sistemas de Informações Geográficas (SIG), tem sido possível $\mathrm{o}$ processamento rápido e eficiente dos dados necessários para caracterização das variáveis morfométricas do terreno (OLIVEIRA, 2002), essenciais para análise das intervenções antrópicas em bacias hidrográficas.

Vale ressaltar que o novo Código Florestal nos últimos anos sofreu diversas alterações pertinentes à adequação ambiental das propriedades rurais, gerando muitas polêmicas e controvérsias no que diz respeito à implantação deste no estado de Mato Grosso.

Segundo a Lei Complementar $\mathrm{N}^{\circ} 412$, de 13 de dezembro de 2010 que dispõe sobre alterações na Lei Complementar $n^{\circ} 38$, de 21 de novembro de 1995, na Lei Complementar $n^{\circ} 232$, de 21 de dezembro de 2005, Lei Complementar n ${ }^{\circ} 233$, de 21 de dezembro de 2005, a Lei Complementar $n^{\circ} 343$, de 24 de dezembro de 2008 e dá outras providências, diz em seu Art. $1^{\circ}$ : As alíneas e seus itens do Art. 58, da Lei Complementar $n^{\circ} 38$, de 21 de novembro de 1995, que dispõe sobre o Código Estadual de Meio Ambiente passa a vigorar com diferente redação, a qual considera área de preservação permanente as florestas e demais vegetações. Porém, dentre outras alíneas neste levantamento, coube o uso da; a) situadas ao longo de qualquer curso d'água cuja largura era de $50 \mathrm{~m}$ (cinquenta metros), para os cursos d'água de até $50 \mathrm{~m}$ (cinquenta metros) de largura, e que agora permite 30 (trinta) metros para os cursos d'água de menos de 10 (dez) metros de largura e 50 (cinquenta) metros para os cursos d'água que tenham de 10 (dez) a 50 (cinquenta) metros de largura; b) ao redor das lagoas ou lagos e reservatórios d'água naturais ou artificiais, represas hidrelétricas ou de uso múltiplo, em faixa marginal, cuja largura mínima era de $100 \mathrm{~m}$ (cem metros) que passa a ser $50 \mathrm{~m}$ (cinquenta metros); c) nas nascentes, ainda que intermitentes, os chamados "olhos d'água", qualquer que seja sua situação topográfica, nas veredas e nas cachoeiras ou quedas d'água, num raio mínimo de $100 \mathrm{~m}$ (cem metros) vindo a vigorar a um raio mínimo de $50 \mathrm{~m}$ (cinquenta metros). Voltando mesmo que temporariamente a valer não mais restritivamente que a Lei 4.771 de 1965 que institui o Código Florestal Brasileiro.
O ministro do Superior Tribunal de Justiça Antonio Hermann Benjamin, diz que a legislação brasileira é uma das melhores do mundo com respeito à questão ambiental, porém, o grande problema está na sua aplicação. Essas áreas são protegidas por lei, entretanto, na prática, a realidade é muito diferente (MATSUBARA, 2006).

A partir do ano 2000, o Estado de Mato Grosso implantou o Sistema de Licenciamento Ambiental em Propriedades Rurais de Mato Grosso (SLAPR) que tem como objetivo principal controlar e reduzir os desmatamentos irregulares de vegetação nativa nas áreas rurais do estado. Ao SLAPR sucedeu a partir de 2006 - 2007 o Sistema Integrado de Monitoramento e Licenciamento Ambiental (SIMLAM). Os imóveis rurais são cadastrados no sistema por adesão voluntária do proprietário ou por notificação da SEMA-MT (ISA, 2006; BERNASCONI et al., 2009).

Objetivou-se com esse trabalho elaborar mapas de conflito de uso do solo com base na legislação ambiental, e uso de geotecnologias voltadas para a melhor conservação da floresta nativa em uma área de 17.759 ha do município de Alta Floresta - MT, visando ao mapeamento dos fragmentos de florestas naturais, delimitando as áreas de preservação permanente ao redor das nascentes e ao longo de matas ciliares, conforme a Lei Complementar $\mathrm{n}^{\circ}$ 412, demonstrando a aplicabilidade da utilização associada ao Sensoriamento Remoto e Geoprocessamento no planejamento e conservação da área estudada.

\section{MATERIAL E MÉTODO}

\section{Caracterização da área de estudo}

O estudo foi realizado em uma área de 17.759 ha, referente a uma microbacia localizada no município de Alta Floresta, no extremo norte do estado de Mato Grosso, a 830 km da capital Cuiabá, situada entre as coordenadas geográficas $09^{\circ} 52^{\prime} 32^{\prime \prime}$ de Latitude Sul e $56^{\circ} 05^{\prime} 10^{\prime \prime}$ de Longitude Oeste (Figura 1).

Segundo a classificação realizada pela SEPLAN (2006), Alta Floresta encontra-se na zona I B3a, caracterizando-se por um clima equatorial continental úmido com estação seca definida da depressão sul-amazônica, com temperatura média anual entre 24,3 e $24,8^{\circ} \mathrm{C}$. O volume de precipitação pluviométrica é elevado ficando entre 2000 e 2300 $\mathrm{mm}$. 


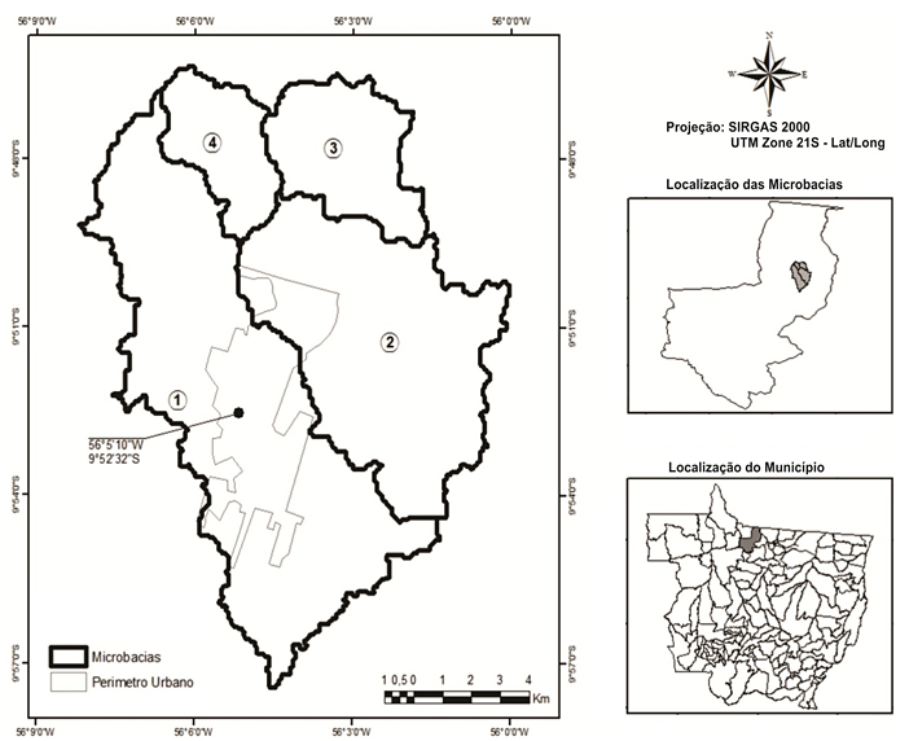

FIGURA 1: Localização da área em estudo, município de Alta Floresta - MT.

FIGURE 1: Location of the study area, in the municipality of Alta Floresta - MT.

O relevo é formado pelo Planalto Apiacás - Sucurundi e a Depressão Interplanáltica da Amazônia Meridional (FERREIRA, 2001). A cobertura vegetal dominante no município é do tipo Floresta Ombrófila Aberta Tropical que ocorre associada a palmeiras e cipós. Este tipo de floresta caracteriza-se pela presença de árvores de grande porte bastante espaçadas, pelo frequente grupamento de palmeiras e também pela enorme quantidade de fanerófitas sarmentosas. Entre as espécies de valor econômico encontradas destacamse a castanheira (Bertholletia excelsa), o mogno (Swietenia macrophylla) e o cedro (Cedrella odorata) (OLIVEIRA, 2006).

\section{Base de dados utilizada}

Foi utilizada uma imagem de satélite do sensor orbital franco-belga-sueco de alta resolução espacial SPOT 5, obtida no ano de 2008, composta pelas bandas 1,2 e 3 . A banda 1 atuando na faixa espectral $(\mu \mathrm{m})$ 0,49-0,61 (Azul), banda 2 na faixa 0,61-0,68 (Vermelho) e a banda 3 na faixa 0,78-0,89 (Infravermelho Próximo). Sua resolução espacial é de 2,5 metros e sua resolução radiométrica é de 8 bits (RODRIGUES, 2005).

A imagem utilizada foi obtida através de parceria com a Secretaria Municipal de Meio Ambiente e a ONG ICV (Instituto Centro de Vida). Os demais vetores como hidrografia e microbacias foram cedidos pela secretaria do seu banco de dados.

\section{Procedimentos Metodológico}

Os procedimentos metodológicos foram divididos em três etapas sendo elas: Préprocessamento dos dados, Processamento dos dados e Manipulação dos dados processados. Utilizou o software ArcGis 9.2 e ENVI 4.1, para os processamentos dos dados vetoriais, classificação da imagem e cruzamento entre as informações mapeadas.

\section{Pré-processamento dos dados}

Nesta etapa foram realizados os procedimentos necessários para se preparar a cena do sensor SPOT 5 e vetorizar as feições de interesse para o estudo. A imagem foi composta com as respectivas bandas Vermelho 1 (R), Verde 2 (G) e Azul 3 (B) e também Ortorretificada, projetada para o Datum SIRGAS 2000 (Sistema de Referência Geocêntrico para as Américas), zona 21 $\mathrm{Sul}$, com sistema referencial de localização terrestre baseado em coordenadas métricas UTM (Universal Transverse Mercator).

Após preparação dos arquivos raster, partiuse para a preparação dos arquivos vetoriais, em que todos foram manipulados no software ArcGIS 9.2. Para as nascentes foi criado um arquivo no formato ponto, estas foram vetorizadas no ArcMap (modulo do ArcGIS 9.2) de forma a inserir um ponto na extremidade dos braços de rio. 


\section{Processamento dos dados}

De posse da imagem e dos vetores deu-se início ao processamento dos dados. O primeiro processamento foi a criação de um buffer junto às nascentes e cursos d'água. O buffer consiste em inserir uma linha equidistante em ambos os lados das feições vetorizadas, a fim de delimitar as Áreas de Preservação Permanente.

Para os cursos de água gerou-se um buffer de 30 metros em ambos os lados da feição, pois nenhum curso de água ultrapassou 10 metros de largura, já para as nascentes e os espelhos d'água, o buffer foi de 50 metros de raio conforme estabelecido na Lei Complementar $n^{\circ} 412$. Depois de criados os buffers para as nascentes e para os cursos de água utilizou-se a função (Merge) do SIG utilizado, com a finalidade de unir estas feições e eliminar as sobreposições.

Logo após realizou-se um recorte (Clip) limitando a região ou área de interesse de trabalho de uma camada vetorial, extraindo desta uma zona de interesse e então da imagem SPOT 5 a área correspondente às microbacias, delimitando a área de estudo e reduzindo o tamanho da mesma para melhorar o processo de classificação.

Depois, realizou-se uma classificação supervisionada do tipo MaxVer no software ENVI 4.2. O classificador utilizado consiste na classificação de um pixel desconhecido, seguindo a condição em que a probabilidade de um vetor assinalado a uma determinada classe deve ser maior ou igual à probabilidade do vetor ser assinalado em qualquer outra classe . Assim, para classificar um determinado vetor, a regra de decisão de máxima verossimilhança computa o valor da probabilidade para cada classe e assinala o pixel da classe que possui o maior valor (MAROTTA et al., 2006).

Foram criadas cinco classes sendo elas: Floresta, Pastagem, Água, Solo Exposto e Ocupação Urbana. Para cada uma destas classes foram coletadas aleatoriamente Pontos de Controle (PCs) do tipo ROI (Region of Interest) que serviram como base no processo de classificação. A resultante do processo de classificação é uma imagem em escala de cinza, na qual é possível definir o arquivo de saída (output) em diversos formatos, optou-se por manter o formato original da imagem em raster de extensão (.tiff).

Posteriormente, converteu-se a imagem de raster para vetor, para melhor manipulação dos dados. Este arquivo vetor apresentou, para cada feição, pequenos polígonos separadamente na tabela de atributos, necessitando gerar apenas um polígono geral para cada feição. Realizou-se então uma união destes com a função (Dissolve), esta reduziu para 5 polígonos referentes às classes de uso.

De posse da classe "Água" foi gerado um buffer de 50 metros, a fim de identificar e delimitar as APPs que se encontram ao redor das lagoas. Contudo, obtiveram-se todos os vetores das APPs de interesse, sendo eles "app_hidrografia", "app_nascentes" e "app_lagoas", cada um com sua metragem específica, e com a função de união (Union) obteve-se a soma destes vetores resultando na APP total da microbacia. As demais formas de APPs não foram contempladas neste trabalho, pois, segundo levantamento feito em dados geográficos, as mesmas não estão presentes na área de estudo.

Por fim, fez-se a sobreposição entre o mapa gerado com a classificação da imagem e o mapa de APP. Este procedimento permitiu avaliar, áreas de vegetação nativa ou áreas com alguma forma de uso, inseridas nos limites das áreas de preservação.

\section{Manipulação dos dados processados}

Após processados os dados, criou-se um campo na tabela de atributos com o nome de "Área" e a partir deste calculou-se a área em hectares de cada classe. Para uma melhor visualização dos resultados, estes foram exportados para o software Microsoft Office Excel versão 2007, no qual os mesmos foram mais bem organizados e apresentados. Por fim foram elaborados os mapas (Layouts) abordando os resultados obtidos através dos processamentos realizados anteriormente.

\section{RESULTADOS E DISCUSSÕES}

Os resultados obtidos de acordo com o levantamento e o processamento dos dados serão analisados e discutidos a seguir.

\section{Feições obtidas por vetorização e geoprocessamento}

A primeira feição foi a área da Microbacia que tem 17.759 ha, o que corresponde a aproximadamente $2 \%$ da área total do município que é de 894.700 ha em consonância com os dados apresentados por IBGE (2007). O total de nascentes encontrado foi de 221.

Ao todo, a APP apresentou uma área total 
de 1.966,51 hectares, o que corresponde a $11,1 \%$ de toda a área da microbacia (Tabela 1 ).

As últimas feições vetorizadas foram os espelhos d'água. Estas em função da classificação, utilizando a classe Água, apresentando uma área de 113,84 ha, que corresponde a $0,6 \%$ da área da microbacia.

\section{Classificação supervisionada}

Foram criados 40 pontos de controle (PCs) para a feição floresta, 40 para pastagem, 40 para água, 20 para solo exposto e 20 para ocupação urbana totalizando 160 PCs. Na Figura 3 é apresentado o mapa de classes de cobertura do solo, obtido pela classificação.

\section{Tabela de atributos da classificação}

$\mathrm{Na}$ Tabela 1 são apresentas as classes de cobertura do solo mapeadas e as respectivas áreas de ocorrência.

Das classes de cobertura do solo mapeadas, a classe pastagem foi a que apresentou maior área, com 938,32 ha, representando 47,7\% da APP da área levantada. Esta, também chamada de vegetação rasteira por alguns autores, possui indivíduos em grande parte herbáceos, na qual pode haver áreas subutilizadas e em processo de regeneração.

Dentre os conflitos na forma de uso dos recursos naturais e da terra, destacam-se as áreas que se destinam ao desenvolvimento das atividades pecuárias. A retirada da vegetação para a formação das pastagens foi realizada de forma desordenada e com a inexistência de qualquer tipo de precaução com as áreas de preservação permanente (SILVA e CARMO, 2010).

A classe Floresta apresentou área de 777,57 ha, equivalente a $39,5 \%$ da APP, que podem ser vegetação arbórea ou arbustiva, abrangendo desde indivíduos de grade porte ou clímax, até indivíduos de pequeno porte ou secundários como áreas de sucessão, que são de muita importância para as áreas de preservação.

As classes identificadas como solo exposto e ocupação urbana apresentaram, respectivamente, 26,46 e 110,12 ha correspondentes a 1,3 e 5,6\%. Essas ocupações podem ser consideradas as mais críticas, pois acarretam impactos ambientais muitas vezes irreversíveis para esse ambiente. O solo exposto na maioria das vezes antecede a ocupação urbana e quando isso não ocorre, dá lugar à agricultura que, segundo Trabaquini et al. (2009), quando executada de forma inadequada é uma das fontes de poluição do solo e da água, devido à utilização em excesso de defensivos e insumos agrícolas. A ocupação urbana também contribui para a degradação das áreas de APP, sendo estas áreas de grande pressão antrópica, ocupadas por edificações irregulares causando compactação do solo, favorecendo o assoreamento dos cursos de água e estando altamente susceptíveis ao lançamento de dejetos nos cursos de água

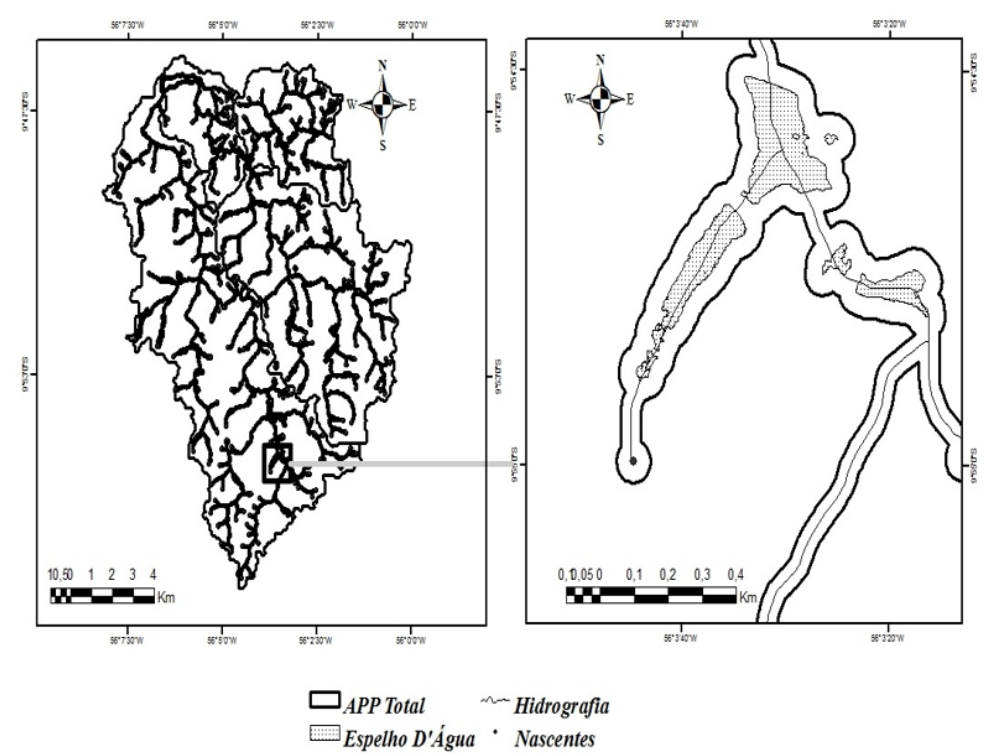

FIGURA 2: Feições obtidas por vetorização e geoprocessamento, na área da microbacia.

FIGURE 2: Features obtained by vectorization and geoprocessing in the area of the microbasin. 

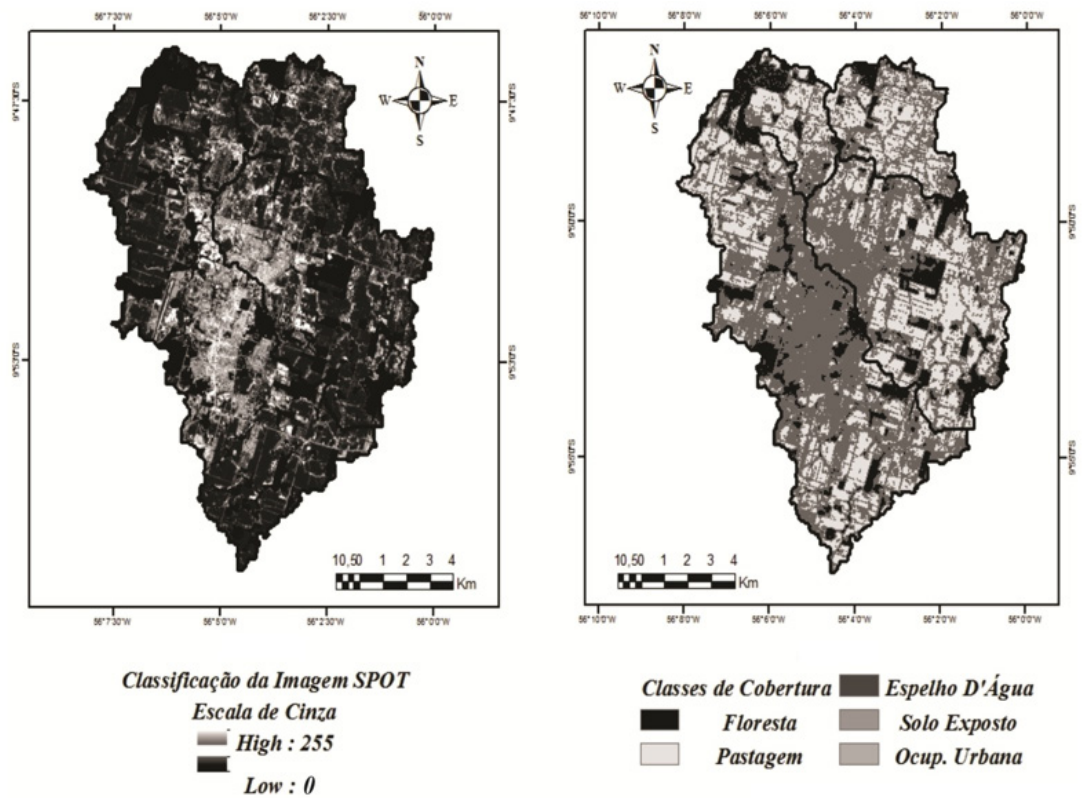

FIGURA 3: Resultado da classificação MaxVer na área de estudo. Município de Alta Floresta - MT. FIGURE 3: Result of classification MaxVer in the study area. Municipality of Alta Floresta - MT.

TABELA 1: Tabela de atributos da classificação, referente aos tipos de uso do solo.

TABLE 1: Table of attributes in classification, referring to the types of land use.

\begin{tabular}{ccc}
\hline Classe de cobertura & Área (ha) & Área (\%) \\
\hline Floresta & 777,75 & 39,5 \\
Pastagem & 938,32 & 47,7 \\
Espelho d'água & 113,84 & 5,7 \\
Solo exposto & 26,48 & 1,3 \\
Ocupação urbana & 110,12 & 5,6 \\
\hline TOTAL & $1.966,51$ & 100,00 \\
\hline
\end{tabular}

produzidos pelos moradores locais.

\section{Avaliação dos conflitos de uso do solo}

Os procedimentos adotados nessa etapa foram baseados na metodologia empregada por Oliveira (2002) sendo delimitadas as Áreas de Preservação Permanentes ao redor de nascentes e ao longo de matas ciliares, tendo como referência os limites estabelecidos pela Lei vigente. Uma vez determinadas as áreas de preservação permanente, estas foram confrontadas com o Mapa de Uso do Solo, no qual foi possível verificar as áreas que estão em conflito.

As áreas em conflito estão relacionadas às feições de ação do homem, sendo: a pastagem, solo exposto e ocupação urbana, isto quer dizer, locais em que a vegetação nativa sofreu algum tipo de intervenção. Essas áreas representaram um total de $1.074,92$ ha, ou seja, 54,6\%.

Bernasconi et al. (2009) desenvolveram o projeto de Avaliação Ambiental Integrada do Território Portal da Amazônia, no qual os municípios desta região tiveram resultados, tais como a dinâmica de desmatamento por município, que do ano 2000 até o ano de 2007 para o município de Alta Floresta houve uma evolução de 3.698 ha (41,3 \%) para 4.644 ha, representando $51,9 \%$ de área desmatada. Também avaliaram o desmatamento em APP nos municípios, e Alta Floresta apresentou um total de $1.132 \mathrm{~km}^{2}$, e deste, $558 \mathrm{~km}^{2}$, ou seja, $49,3 \%$ encontram-se desmatados.

Ainda neste projeto, foi realizado um estudo de caso no Município de Alta Floresta para diagnosticar com mais detalhe o nível de degradação da APP. Selecionando 4 microbacias dentre as 


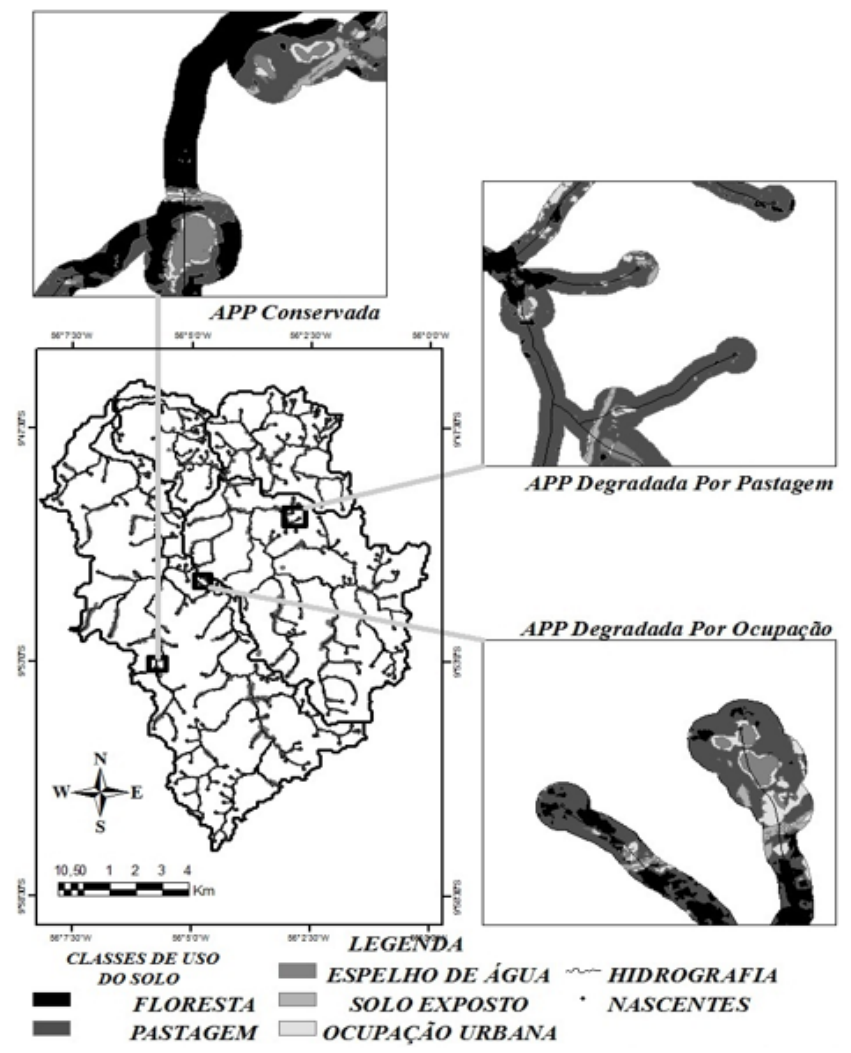

FIGURA 4: Tipos de uso do solo de uma microbacia do Município de Alta Floresta - MT. FIGURE 4: Types of land use in a microbasin in the municipality of Alta Floresta - MT.

mais críticas, e juntas compreendendo uma área de 14.180 ha, com mais de $50 \%$ de sua área em solo exposto, agricultura, pasto e ocupação humana, somando mais de 8,5 mil hectares. A distribuição geográfica dos níveis de degradação das APPs mostra que as bacias com APPs mais degradadas se localizam próximas ao centro urbano, apresentando níveis entre 74 e 100 \% de degradação, coincidindo também com as áreas de assentamentos e agricultura familiar.

Diagnósticos de conflitos de uso do solo através de técnicas de geoprocessamento servem como subsídio para os órgãos públicos municipais na tomada de decisões em eventuais intervenções que poderão ocorrer em anos subsequentes nas Áreas de Preservação Permanente. Principalmente, tratando-se de atividades de recuperação, monitoramento de desmatamentos e estudos de diversidade de flora e a fauna.

\section{CONCLUSÕES}

Pôde-se concluir que a imagem de alta resolução do sensor SPOT 5 mostrou-se apropriada para identificação e mapeamento das classes de cobertura do solo da área estudada, devido ao seu alto grau de detalhamento. As fisionomias pastagem, solo exposto e ocupação urbana representam $(54,66 \%)$ da APP. Um total de 39,5\% da área de APP da microbacia encontra-se com vegetação nativa.

\section{REFERÊNCIAS BIBLIOGRÁFICAS}

ATTANASIO C. M et al. Adequação Ambiental de Propriedades Rurais Recuperação de Áreas Degradadas Restauração de Matas Ciliares. Universidade de São Paulo. Piracicaba - SP. 2006. $65 \mathrm{p}$.

BERNASCONI, P.; SANTOS, R. R.; MICOL, L.; RODRIGUES, J. A. Avaliação Ambiental Integrada: Território Portal da Amazônia. 1. ed. Alta Floresta: ICV, 2009. v. 2000. 108 p .

CARVALHO, M. S. B. S. et al. Caracterização do uso e ocupação do estuário e entorno do Rio Pirangi (CE). In: SIMPÓSIO BRASILEIRO DE SENSORIAMENTO REMOTO, 11., 2003, Belo Horizonte. Anais... Belo Horizonte: INPE, 2003. 
p. $1525-1532$.

FERNANDES, M. F. Avaliação da Aptidão Agrícola das Terras de Parte do Setor Leste da Bacia do Rio Seridó usando Sensoriamento Remoto e Geoprocessamento. 1997. 185 f. Dissertação (Mestrado) - Universidade Federal da Paraíba, Campina Grande, 1997.

FERREIRA, J. C. V. Mato Grosso e Seus Municípios. Cuiabá: Secretaria de Estado de Educação, 2001.

FLORENZANO, T. C. Imagens de Satélite para Estudos Ambientais. São Paulo: Oficina de Textos, 2002.

FORMAGGIO, A. R.; ALVES, D. S.; EPIPHANIO, J. C. N. Sistemas de Informações Geográficas na obtenção de mapas de aptidão agrícola e de taxa de adequação de uso das terras. Revista Brasileira de Ciências do Solo, Campinas, v. 16, p. 249-256, 1992.

IBGE-Instituto Brasileiro de Geografia e Estatística. Censo 2007. Disponível em: $<$ http://www.ibge.gov. $\mathrm{br} / \mathrm{cidadesat} / \mathrm{painel} / \mathrm{painel}$.php? codmun $=510025 \#$ >. Acesso em 30 de abril de 2011.

ISA - Instituto Socioambiental. Sistema de licenciamento ambiental em propriedades rurais no estado de Mato Grosso: análise de sua implementação. Brasília-DF: MMA, 2006. 177 p.

MATSUBARA, C. Sociedade precisa se mobilizar para salvar as APP's. Revista Rede Pela Mata. 2006. Disponível em: < http://sispub.oktiva.com. br/oktiva.net/1320/nota/23541>. Acesso em $30 \mathrm{de}$ abril de 2011.

MAROTTA, G. S. et al. . Avaliação de Métodos de Contraste Aplicados em Imagens Orbitais. In: ENCONTRO DE UTILIZADORES DE SISTEMAS DE INFORMAÇÃO GEOGRÁFICA, 9., 2006, Lisboa. Anais... Lisboa, 2006.

OLIVEIRA, A. S. Solos em sistema agroflorestal na Amazônia meridional. Dissertação (Mestrado em Solos e Nutrição de Plantas) - Universidade Federal de Viçosa, Viçosa, 2006.

OLIVEIRA, M. J. Proposta Metodológica para Delimitação Automática de Áreas de Preservação Permanente em Topos de Morros e em Linha de Cumeada. 2002. 53 p. Dissertação (Mestrado em Ciência Florestal) - Universidade Federal de Viçosa, Viçosa, 2002.

RODRIGUES, A. C. M. Sensoriamento Remoto e Geoprocessamento aplicados na Análise da Legislação Ambiental do Município de São Sebastião (SP). 2005. 217 f. Disertação (Mestrado em Geografia Humana). Faculdade de Filosofia, Letras e Ciências Humanas. Universidade de São Paulo, São Paulo, 2005.

RODRIGUES, T. E. Solos da Amazônia. In: O Solo nos Grandes Domínios Morfoclimáticos do Brasil e o Desenvolvimento Sustentado. Viçosa: SBCS; UFV; DPS, 1996.

SCHNEIDER, S., TARTARUGA, I. G. P. Território e Abordagem Territorial: das referências cognitivas aos aportes aplicados à análise dos processos sociais rurais. Raízes, Campina Grande, v. 23, n. 1, p. 99-116, 2004.

SECRETARIA DE ESTADO DE PLANEJAMENTO E COORDENAÇÃO GERAL (SEPLAN). Unidades Climáticas do Estado de Mato Grosso. In: Zoneamento Sócio Econômico Ecológico. Cuiabá: PRODEAGRO. CD-Rom do Atlas Climatológico de Mato Grosso. Governo do Estado de Mato Grosso. Secretaria de Estado de Planejamento e Coordenação Geral. Laboratório de Climatologia. Universidade Federal do Estado de Mato Grosso, 2006.

SILVA, J. R. P.; CARMO, E. M. Estudo dos Conflitos Ambientais no Assentamento E App's do Igarapé do Bruno - Apiacás-MT. In: SIMPÓSIO BRASILEIRO DE CIÊNCIAS GEODÉSICAS E TECNOLOGIAS DA GEOINFORMAÇÃO, 3., 2010, Recife. Anais... Recife, 2010. p. 001-009.

TRABAQUINI, K. et al. Avaliação das APPs em áreas de fundo de vale na cidade de Londrina-PR utilizando imagens de alta resolução. INPE In: Simpósio Brasileiro de Sensoriamento Remoto, 14., 2009, Natal. Anais... Natal, 2009.

VIANA, V. M.; TABANEZ, A. J. A.; MARTINEZ, J. L. A. Restauração e manejo de fragmentos florestais. In: CONGRESSO NACIONAL SOBRE ESSÊNCIAS NATIVAS, 2., 1992, Campos do Jordão. Anais... Campos do Jordão: Instituto Florestal/Secretaria do Meio Ambiente, 1992. p. $400-406$. 